\title{
Emergency nurse practitioner services in major accident and emergency departments: a United Kingdom postal survey
}

\author{
Christopher C Tye, Fiona Ross, Sally M Kerry
}

\begin{abstract}
Objective-To establish the current and predicted distribution of formal emergency nurse practitioner services in major accident and emergency departments in the United Kingdom; to determine organisational variations in service provision, with specific reference to funding, role configuration, training, and scope of clinical activity.
\end{abstract}

Methods-Postal survey of senior nurses of all major accident and emergency departments in the United Kingdom ( $n=$ 293) in May/June 1996.

Results-There were 274 replies (94\% response rate): 98 departments (36\%) provided a formal service; a further 91 departments (33\%) reported definite plans to introduce a service by the end of 1996; smaller departments, under 40000 less likely to provide a service than busier units $\left(\mathbf{p}<0.001, \chi^{2}\right.$ for trend). Three different methods of making the role operational were identified: dedicated, integrated, and rotational. Only $16(18 \%)$ were able to provide a 24 hour service; 91 departments (93\%) employed emergency nurse practitioners who had received specific training, but wide variations in length, content, and academic level were noted; 82 departments (84\%) authorised nurse practitioners to order $x$ rays independently, but only 35 (36\%) allowed them to interpret radiographs; 67 (68\%) permitted "over the counter" drug supplying under local protocol, and 52 (54\%), "prescription only" drug supplying from an agreed list.

Kingston University and St George's Hospital Medical School, London SW17, UK:

Faculty of Healthcare Sciences C C Tye

F Ross

Department of General Practice and Primary Care S M Kerry

Correspondence to: Chris Tye, 82 Meadowview Road, West Ewell, Surrey KT19 9UA, UK.

Accepted for publication 21 August 1997

Conclusions-Formal emergency nurse practitioner services are provided in all parts of the United Kingdom, with predicted figures suggesting a rapidly accelerating upward trend. Wide variations in service organisation, training, and scope of activity are evident.

(F Accid Emerg Med 1998;15:31-34)

Keywords: emergency nurse practitioners; operational role; emergency services

The interface between medical and nursing roles has become the focus of increasing attention in recent years. In accident and emergency (A\&E) departments, the inexorable rise in patient attendances, ${ }^{1}$ combined with medical staffing shortfalls, ${ }^{2}$ has highlighted the need for new patient attendances annually, were

a review of traditional role boundaries. The changing attitude of nursing's professional regulatory bodies towards role innovation and expansion has also created a climate conducive to change. ${ }^{34}$ As a result, a significant boost has been given to the role of the emergency nurse practitioner (ENP), first described in England in the mid $1980 \mathrm{~s}^{5}$ but with a longer history in north America. ${ }^{6}$ Previous studies have attempted to map activity in this area, ${ }^{7-9}$ but because of a somewhat ambiguous definition of the role of the ENP, none has provided a full United Kingdom perspective. Furthermore, rapid policy change and recent rationalisation of major $A \& E$ department provision in the United Kingdom have highlighted the need for a current, comprehensive database to reliably inform local and national policy decisions.

The aim of this study was to establish the distribution of formal ENP services in major $A \& E$ departments in the United Kingdom, and to determine the organisational variations in service provision, with particular reference to funding, role configuration, training, and scope of activity.

\section{Methods}

In May 1996, a structured postal questionnaire, previously piloted locally in the South Thames Region, was sent to the senior nurse of all major $A \& E$ departments $(n=293)$ listed in the 1996 edition of the Directory of emergency and special care units (CMA Medical). Minor injury units, specialist ophthalmic units, and Ministry of Defence facilities were excluded from the study. A follow up letter was sent to non-respondents after four weeks.
OPERATIONAL DEFINITION

Previous studies ${ }^{7}{ }^{9}$ have described an "unofficial" role for the ENP, but this was felt to be at variance with the current concept of an authorised role. It also raises medicolegal concerns, particularly from the point of view of vicarious liability. ${ }^{10}$ Therefore for the purposes of the present study an emergency nurse practitioner service was defined as "a formally recognised clinical service provided within an accident and emergency department by one or more designated qualified nurses, authorised to independently assess, treat, and discharge predefined categories of patients."

The categorical data collected were compared using $\chi^{2}$ tests or Fisher's exact tests where frequencies were small. 
Table 1 Distribution of emergency nurse practitioner services in the United Kingdom

\begin{tabular}{llll}
\hline $\begin{array}{l}\text { Country (No of } \\
\text { departments) }\end{array}$ & $\begin{array}{l}\text { No (\%) providing } \\
\text { ENP service in May } \\
1996\end{array}$ & $\begin{array}{l}\text { No (\%) planning to } \\
\text { provide ENP service by } \\
\text { end 1996 }\end{array}$ & $\begin{array}{l}\text { Total No (\%) predicted to be } \\
\text { providing ENP service by end } \\
1996\end{array}$ \\
\hline England ( $\mathrm{n}=208)$ & $85(41)$ & $74(35)$ & $159(76)$ \\
Wales $(\mathrm{n}=15)$ & $3(20)$ & $1(7)$ & $4(27)$ \\
Scotland ( $\mathrm{n}=35)$ & $5(14)$ & $11(32)$ & $16(46)$ \\
N Ireland ( $\mathrm{n}=16)$ & $5(31)$ & $5(31)$ & $10(62)$ \\
UK total $(\mathrm{n}=274)$ & $98(36)$ & $91(33)$ & $189(69)$ \\
\hline
\end{tabular}

ENP, emergency nurse practitioner.

Table 2 Regional distribution of ENP services in England

\begin{tabular}{llll}
\hline & $\begin{array}{l}\text { No (\%) of } \\
\text { departments with } \\
\text { ENP service in May } \\
\text { Region (No of depts) }\end{array}$ & $\begin{array}{l}\text { No (\%) planning to } \\
\text { provide ENP service } \\
\text { by end 1996 }\end{array}$ & $\begin{array}{l}\text { Total no (\%) predicted to } \\
\text { be providing ENP service } \\
\text { by end 1996 }\end{array}$ \\
\hline Northern \& Yorks (n=29) & $8(28)$ & $13(44)$ & $21(72)$ \\
Trent ( $\mathrm{n}=16)$ & $5(31)$ & $8(50)$ & $13(81)$ \\
Anglia \& Oxford (n=18) & $6(33)$ & $5(28)$ & $11(61)$ \\
North Thames (n=32) & $17(53)$ & $11(35)$ & $28(88)$ \\
South Thames (n=32) & $18(56)$ & $7(22)$ & $25(78)$ \\
South West (n=27) & $11(41)$ & $9(33)$ & $20(74)$ \\
West Midlands $(\mathrm{n}=22)$ & $8(36)$ & $8(36)$ & $16(72)$ \\
North \& West $(\mathrm{n}=32)$ & $12(38)$ & $13(40)$ & $25(78)$ \\
\hline
\end{tabular}

ENP, emergency nurse practitioner.

Table 3 Distribution of United Kingdom ENP services in relation to annual new patient attendances

\begin{tabular}{lcll}
\hline $\begin{array}{l}\text { Annual new patient } \\
\text { attendances }\end{array}$ & $\begin{array}{l}\text { Number of } \\
\text { departments }\end{array}$ & $\begin{array}{l}\text { Number (\%) with ENP } \\
\text { service in May 1996 }\end{array}$ & $\begin{array}{l}\text { Predicted number (\%) with } \\
\text { ENP service by end 1996 }\end{array}$ \\
\hline $0-39999$ & 89 & $15(17)$ & $45(51)$ \\
$40-59999$ & 111 & $45(41)$ & $85(77)$ \\
$60-79999$ & 50 & $27(54)$ & $38(76)$ \\
$>80000$ & 24 & $11(46)$ & $21(88)$ \\
\hline
\end{tabular}

$\chi^{2}$ test for trend $\mathrm{p}<0.001$.

ENP, emergency nurse practitioner.

Table 4 Distribution of factors preventing ENP role development in departments not currently providing a service $(n=176)$

\begin{tabular}{lcllll}
\hline Factors & $\begin{array}{l}\text { UK total, } \\
n=176(\%)\end{array}$ & $\begin{array}{l}\text { England, } \\
n=123(\%)\end{array}$ & $\begin{array}{l}\text { Wales, } \\
n=12(\%)\end{array}$ & $\begin{array}{l}\text { Scotland, } \\
n=30(\%)\end{array}$ & $\begin{array}{l}\text { N Ireland, } \\
n=11(\%)\end{array}$ \\
\hline Funding & $106(60)$ & $75(61)$ & $10(83)$ & $15(50)$ & $6(55)$ \\
Lack of medical support & $49(28)$ & $31(25)$ & $3(25)$ & $8(27)$ & $7(54)$ \\
Medicolegal concerns & $33(19)$ & $20(16)$ & $2(17)$ & $9(30)$ & $2(18)$ \\
Lack of nursing support $^{\star}$ & $21(12)$ & $14(11)$ & $0(0)$ & $2(7)$ & $5(46)^{\star}$ \\
\hline
\end{tabular}

${ }^{\star} \mathrm{p}<0.05$, Fisher's exact test.

ENP, emergency nurse practitioner.

\section{Results}

In all, 274 completed questionnaires were returned, giving a United Kingdom response rate of $94 \%$.

Ninety eight emergency nurse practitioner services were reported operational in major A\&E departments in the United Kingdom ( $36 \%$ of the sample), although there was some variation between countries. Respondents were asked whether they had definite plans to introduce a service before the end of 1996 (table 1).

Although activity levels were relatively higher in England overall, there were variations between the eight regions, with current provision at its highest in the two Thames regions (table 2).

Emergency nurse practitioner schemes were less likely in departments seeing under 40000 new patients per year, compared with busier units ( $p<0.001, \chi^{2}$ for trend, table 3$)$. The senior nurses in the 176 departments in the United Kingdom not currently offering a service were asked to indicate whether, in their view, funding problems, lack of medical or nursing support for the role, or medicolegal concerns had inhibited the implementation of a service (table 4). Lack of funding was identified by 106 respondents $(60 \%)$ and lack of medical support by $49(28 \%)$. In Northern Ireland, lack of nursing support was a more prominent feature compared with the other countries surveyed ( $p<0.05$, Fisher's exact test).

Thirty $(31 \%)$ of the 98 United Kingdom departments currently providing a service had established the role within the previous year of the survey. In England, 45 departments (53\%) had received initial funding to establish their services, compared with two $(40 \%)$ in Northern Ireland, one (20\%) in Scotland, and none in Wales.

OPERATIONAL MODELS

Analysis of comments made in response to the question "In your department, is the ENP role combined with any other specific activity?" identified three different operational models. Twenty six departments (27\%), all in England, reported using a dedicated role approach in which the ENPs were permanently employed in that capacity and did not take on any other duties. In contrast, 53 departments (54\%) had developed an integrated model, in which the role was combined with other nursing duties, often on an ad hoc basis. Fourteen (14\%) made the role operational on a rotational basis, with the ENPs rostered in that specific capacity for a defined period, after which they returned to their conventional role. Five departments failed to specify which approach they adopted.

Across the sample as a whole, the mean number of ENPs employed per department was 6.4 whole time equivalents (WTE), although there was a wide range, from 1 to 22 . Where the role was dedicated, the numbers involved were smaller (mean 4.2 WTE), compared with the integrated and rotational models (mean 7.8 WTE). The commonest clinical grade that the ENPs were employed on was $\mathrm{G}(48 \%)$, although $31 \%$ were $\mathrm{F}$ grade and $12 \%$ were E grade. Only $9 \%$ of the sample were employed on grades higher than G. Relatively few services were offered on a 24 hour basis ( 16 out of $98,19 \%$ ), with most operating during daytime hours. Only one department with dedicated ENPs was able to provide a 24 hour service.

EDUCATION AND TRAINING FOR THE ROLE

Ninety one (93\%) of the departments in the United Kingdom currently providing a service employed ENPs who had received some form of education or training for the role. However, there were wide variations evident. Fifty five departments $(60 \%)$ provided training inhouse, with $30(33 \%)$ receiving training from a relatively small number of external establishments. Frequent mention (24 of 30) was made of specific short, unaccredited courses of one or two weeks' duration, offered by a core of trusts with experience of running ENP services. Thirty two respondents $(33 \%)$ felt current provision was inadequate and highlighted specific concerns about a lack of standardisation and nationally recognised 
Table 5 Distribution of perceived benefits of providing an ENP service by departments with a service in May $1996(n=98)$

\begin{tabular}{lllll}
\hline Benefits & $\begin{array}{l}\text { UK total } \\
(\%), n=98\end{array}$ & $\begin{array}{l}\text { Dedicated } \\
\text { ENP role (\%), } \\
n=26\end{array}$ & $\begin{array}{l}\text { Integrated } \\
\text { ENP role (\%), } \\
n=53\end{array}$ & $\begin{array}{l}\text { Rotational } \\
\text { ENP role (\%), } \\
n=14\end{array}$ \\
\hline Improved waiting times & $75(77)$ & $24(92)$ & $39(74)$ & $12(86)$ \\
Increased job satisfaction for ENPs & $33(34)$ & $6(23)$ & $24(45)$ & $3(21)$ \\
Improved quality of care & $25(26)$ & $12(46)$ & $8(15)^{\star}$ & $5(36)$ \\
Increased patient satisfaction & $22(22)$ & $6(23)$ & $14(26)$ & $2(14)$ \\
Better use of resources & $12(12)$ & $5(19)$ & $6(11)$ & $1(7)$ \\
Care more holistic & $11(11)$ & $4(15)$ & $6(11)$ & $1(7)$ \\
Improved continuity of care & $10(10)$ & $3(12)$ & $6(11)$ & $1(7)$ \\
\hline
\end{tabular}

${ }^{\star} \mathrm{p}<0.01$ Fisher's exact test.

ENP, emergency nurse practitioner.

Table 6 Distribution of perceived problems of providing an ENP service by departments providing a service in May $1996(n=98)$

\begin{tabular}{lllll}
\hline & $\begin{array}{l}\text { UK total } \\
(\%), n=98\end{array}$ & $\begin{array}{l}\text { Dedicated } \\
\text { ENP role (\%), } \\
n=26\end{array}$ & $\begin{array}{l}\text { Integrated } \\
\text { ENP role (\%), } \\
n=53\end{array}$ & $\begin{array}{l}\text { Rotational } \\
\text { ENP role (\%), } \\
n=14\end{array}$ \\
\hline $\begin{array}{l}\text { Problems } \\
\begin{array}{l}\text { Opposfing difficulties } \\
\text { groups }\end{array}\end{array}$ & $32(31)$ & $1(4)$ & $29(55)^{\star}$ & $2(14)$ \\
$\begin{array}{l}\text { Funding } \\
\text { Limitations of protocols }\end{array}$ & $22(22)$ & $6(23)$ & $11(21)$ & $5(36)$ \\
Medicolegal concerns & $21(21)$ & $8(31)$ & $11(21)$ & $2(14)$ \\
& $6(6)$ & $3(12)$ & $2(4)$ & $1(7)$ \\
& $5(5)$ & $0(0)$ & $4(8)$ & $1(7)$ \\
\hline
\end{tabular}

${ }^{\star} \mathrm{p}<0.001, \chi^{2}$ test.

ENP, emergency nurse practitioner.

accreditation. Problems with local availability of courses were also identified, particularly in Northern Ireland.

SCOPE OF PRACTICE

Information was requested about ENP activity, independent of a medical practitioner, in several key clinical areas. Eighty two departments (84\%) authorised the ENPs to request $x$ rays, but only $35(36 \%)$ allowed $x$ ray interpretation. Sixty seven $(68 \%)$ reported authorised ENP activity under local protocol, in the area of "prescribing," or more accurately, supplying medications from pharmacyonly and general sales list. Fifty two departments (54\%) permitted ENPs to supply under protocol from an agreed list of prescriptiononly medicines.

In the United Kingdom as a whole, 78 $(80 \%)$ of the 98 departments with a current ENP service stated they had definite plans to develop provision further, either by expanding local protocols to enlarge the scope of practice, or by increasing the number of available ENPs. The most commonly identified benefit of providing an ENP service was a reduction in waiting times (75 of $98,77 \%$, table 5). Departments using dedicated and rotational roles perceived this approach as improving the quality of care, compared to the integrated role $(p<0.01$, Fisher's exact test). The problem most often perceived by the respondents was staffing difficulties (32 of 98, 31\%). This was identified as an issue far more frequently by those departments using the integrated role approach, compared to the dedicated and rotational roles ( $p<0.001, \chi^{2}$ test, table 6$)$. Many respondents using the combined approach, indicated that problems were often encountered when departmental workloads increased or staff sickness levels were high. In these situations, it often became difficult to retain the ENP role, particularly when more traditional nursing duties were in danger of being neglected.

\section{Discussion}

The findings indicate varying levels of ENP activity across all parts of the United Kingdom, including Scotland and Northern Ireland, with planned levels of service provision showing a continued rapid growth in most areas, with the exception of Wales. Direct comparisons with earlier studies are problematic, given the changes in population numbers in the last five years and varying definitions. However, the present findings confirm a continued rise from the figure of 49 official schemes in England and Wales in early 1994 given by Meek et $a l,{ }^{9}$ although it should be noted that their projected figure of $63 \%$ by the end of 1995 has proved inaccurate. This emphasises the need for some caution in interpreting the predicted rises in our study, although respondents were asked about definite plans for a relatively short time ahead, and many indicated by their comments that the introduction of a service was imminent.

The perceived lack of medical support for the introduction of the role may reflect uncertainty about the need for this sort of development, particularly in the absence of any robust evidence concerning effectiveness in the United Kingdom setting. The potential professional threat posed by the view that the role is a form of medical substitution ${ }^{11} 12$ may also be a contributory factor. The need for close collaboration between senior nursing and medical staff appears essential before the role is established and during its subsequent development. The establishment and review of local protocols for nurse prescribing is one particular area where such multidisciplinary cooperation is highly desirable. ${ }^{13}$

The way in which the role is put into operation in practice has a number of implications. Most departments appear to be combining the role with other more traditional nursing duties. However, the study indicates that many departments using this approach encounter staffing difficulties in providing a regular service, particularly when compared with the dedicated approach, in which the role is seen as distinct from other duties. While it could be argued that the dedicated model has the potential to deskill ENPs from other more traditional nursing activities, this was not identified as a particular problem by the respondents in this study. The rotational model, currently only used in a minority of departments, does appear to present relatively few staffing problems, as the role is not simultaneously combined with other nursing activities, while overcoming potential concerns about deskilling.

Given the degree of autonomy and the increased responsibility inherent in the role, the issue of education and training is a concern. ${ }^{71}$ While a majority of the sample had received some sort of training, across the United Kingdom as a whole great variations in the length, content, and academic level of courses are evident. This is perhaps not 
surprising as there remains a lack of clarity surrounding definition of the ENP role itself. ${ }^{14}$ The absence of a national standard, combined with the rapid pace of service development, has resulted in a paucity of educational provision specifically for ENPs. This situation is in contrast to that in north America, where nurse practitioner education is more closely regulated and generally offered at Master's degree level. ${ }^{15}$ However, the UKCC has recently indicated that nurse practitioners are to be included in the specialist practice framework currently under development, and there are growing signs of collaborative course development between trusts and higher education establishments in some parts of the country.

Given the current lack of an educational consensus, or indeed agreement on the role and place of nurse practitioners in United Kingdom health care, it is perhaps not surprising that the study also identified considerable variation in the scope of ENP practice. While some departments appear to limit the degree of independence in the key areas of $x$ ray interpretation and supplying drugs under local protocol, to the point where autonomous practice by ENPs must be undermined, others have allowed a wide range of activities to develop. Some evidence is emerging that ENPs can show acceptable levels of competence in the area of $x$ ray interpretation, ${ }^{16}$ but undoubtedly these complex areas demand high levels of training and continued supervision at an advanced level, which appears in many instances to be lacking at present. The need for in-depth pharmacological knowledge, particularly when there is authorisation to prescribe a variety of drugs including prescription-only medications-albeit from a locally agreed list-is essential if minimum safety standards are to be maintained.

CONCLUSIONS

The claimed benefits of providing an ENP service identified in this survey and elsewhere, ${ }^{14}{ }^{17}{ }^{18}$ such as reduced waiting times and improved patient satisfaction, are impor- tant quality indicators. However, the increasingly widespread proliferation of the role further emphasises the importance of obtaining reliable and robust evidence to support such claims. Evaluation studies need to consider both process and outcome variables, as well as the key issue of cost-effectiveness. The influence of different operational models on these factors also requires investigation. In the absence of such data there is a potential danger that this innovative yet still largely untested role will continue to develop in a haphazard unregulated fashion throughout the United Kingdom.

1 Audit Commission. By accident or design? Improving $A \mathcal{E} E$ services in England and Wales. London: HMSO, 1996

Steward AP. Staffing in accident and emergency departments. I Accid Emerg Med 1996;13:412-4.

3 United Kingdom Central Council for Nursing, Midwifery and Health Visiting. The scope of professional practice. London: UKCC, 1992.

4 Tye $C$. The emergency nurse practitioner role in major accident and emergency departments: professional issues and the research agenda. J Adv. Nurs 1997;26:364-70.

5 Head S. The new pioneers. Nursing Times 1988;84:27-8.

6 Winson G, Fox J. Nurse practitioners; the American experience. Br J Nursing 1995;4:1326-9.

7 Read SM, Jones NMB, Williams BT. Nurse practitioners in accident and emergency departments: what do they do? BMJ 1992, 305:1466-9.

8 Crinson I. Impact of the Patient's Charter on A\&E departments. 2: The emergency nurse practitioner. Br J Nursing ments. 2: The 5 .

9 Meek SJ, Ruffles G, Anderson J, Ohiorenoya D. Nurse practitioners in major accident and emergency departments: a national survey. J Accid Emerg Med 1995;12:177-81.

10 Dowling S, Martin R, Skidmore P, Doyal L, Cameron A, Lloyd $S$. Nurses taking on junior doctors' work: a confusion of accountability. BMJ 1996;312:1211-4.

11 Dowling S, Barrett S, West R. With nurse practitioners, who needs house officers? BMJ 1995;311:309-13.

12 Robinson DK. Nurse practitioner or mini-doctor? Accid Emerg Nursing 1993;1:53-5.

13 Marshall J, Edwards C, Lambert M. Administration of medicines by emergency nurse practitioners according to protocols in an accident and em.

14 Dolan B, Dale J, Morley V. Nurse practitioners: the role in A\&E and primary care. Nursing Standard 1997;11:33-8.

15 Price MJ, Martin AC, Newberry YC, Zimmer PA

Price MJ, Martin AC, Newberry YC, Zimmer PA,
Brykczynski KA, Warren B. Developing national guidelines Brykczynski KA, Warren B. Developing national guidelines for nurse practitioner education: an overview

product and process. J Nurs Educ 1992;31:10-15.
16 Freij RM, Duffy T, Hackett D, Cunningham D, Fothergill J. Radiographic interpretation by nurse practitioners in a minor injuries unit. J Accid Emerg Med 1996;13:41-3.

17 Rhee KJ, Dermyer AI. Patient satisfaction with a nurse practitioner in a university emergency service. Ann Emerg Med 1995;26:130-2.

18 James MR, Pyrgos N. Nurse practitioners in accident and emergency departments. Arch Emerg Med 1989;6:241-6. 